技術論文

\author{
과학기술위성 2호 Reaction Wheel Assembly Interface \\ Unit Proto Flight Model 개발 \\ 김세일*, 이성호*, 강경인 ${ }^{*}$
}

\title{
Engineering Model Design and Implementation Proto Flight Model of Reaction Wheel Assembly Interface Unit for STSAT-2
}

Saeil Kim*, Sung-ho Rhee* and Kyungin Kang*

\begin{abstract}
Proto Flight Model of Reaction Wheel Assembly Interface Unit(RIU) for STSAT-2 was developed. The RIU of STSAT2 has three major functions for interface between satellite system and RWAs. It has switches for RWA main power, communication Mux. and communication line driver.

\section{초 록}

과학기술위성 2호 사용되는 구동기인 반작용 휠(Reaction Wheel Assembly, RWA)과 위성 시스템을 연결해주는 인터페이스를 담당하는 Reaction Wheel Assembly Interface Unit(RIU)의 Proto Flight Model의 개발이 완료되고 동작시험을 마쳤다. RIU는 RWA에 공급되는 전원을 켜고 끄는 스위치와 명령을 주고 받는 위성탑재 컴퓨터(OBC)의 통신 회선을 선택하는 멀티플렉서, 그리고 RWA에 연결되는 물리적 통신라인으로 구성된다.
\end{abstract}

Key Words : STSAT-2(과학기술위성 2호), Reaction Wheel(반작용휠)

\section{I. 서 론}

한국과학기술원 인공위성연구센터(KAIST SaTReC) 에서는 우리별1호, 2호, 3호와 2003년 9월 27일 러시아에서 발사되고 궤도에서 성공적으로 주어 진 임무를 수행하는 과학기술위성 1 호에 이어 다 섯 번째 개발 중인 과학기술위성 2호(STSAT-2) 의 Engineering Model(EM)의 개발 및 시험을 마 쳤으며 Proto Flight Model(PFM)을 개발완료하 였다.

STSAT-2의 자세제어에 사용되는 구동기중에서 주된 역할을 수행하는 RWA는 모터와 회전체로 모터구동 전자부로 구성되어있다. 모터를 구동하

† 20005년 3월 31일 접수 2006년 4월 18일 심사완료

* 정회원, KAIST 인공위성연구센터

연락저자, E-mail: sikim@satrec.kaist.ac.kr

대전광역시 유성구 구성동 373-1
여 이에 연결된 회전체를 회전시키면 작용-반작 용 원리에 의해 위성체가 회전하는 기동력이 발 생한다.

과학기술위성2호에서 사용하는 RWA는 상업용 으로 제작된 제품을 구매하여 사용하며, 본 논문 은 이런 RWA와 위성체 시스템 간의 안정적인 연결을 담당하고 $\mathrm{RWA}$ 의 원하는 성능을 발휘하 기 위한 전력공급 및 $\mathrm{OBC}$ 에서 오는 통신을 중 계하고 실제 반작용 휠에 물리적 통신 회선을 제 공하는 역할을 담당하는 RIU EM/PFM의 설계, 개발 및 시험에 대한 내용을 담고 있다.

$$
\text { II. 본 론 }
$$

2. 반작용 횔과 인터페이스 유닛

2.1 과학기술위성 2 호의 반작용 휠

과학기술위성2호에 사용하는 RWA는 독일 


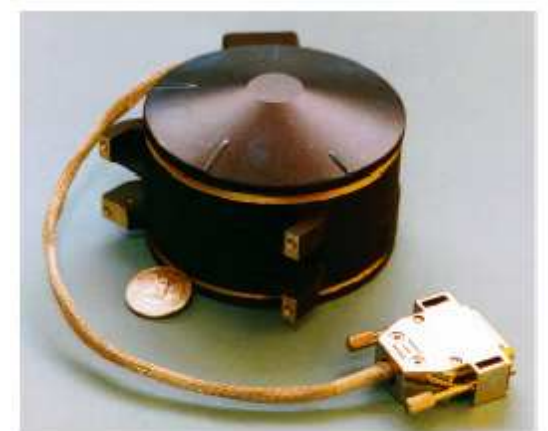

Reaction Wheel Assembiy RSI 01-5/28

그림 1. 과학기술위성2호의 반작용 휠 (RSI 01-5/28)

TELDIX 회사에서 제작한 제품으로 휠 하우징의 내부에 휠을 구동하는 전자회로부가 내장되어있 어서 추가적인 휠 제어 및 구동 전자부가 필요없 다. 따라서 RWA와 시스템의 연결은 구동전력 공급, 통신을 위한 회선 확보와 데이터 처리부분 으로 이루어지며, 이 세가지 부분의 개발이 필요 하다.

$\mathrm{RWA}$ 의 전력은 위성 내부의 전력공급유닛 2(PSU2)에서 공급받으며 RWA의 구동 전압이 위 성의 버스 전압인 $+28[\mathrm{~V}]$ 보다 낮은 전압을 사용 하므로 $\mathrm{DC} / \mathrm{DC}$ converter를 이용하여 전압을 변 환하여 RIU에 공급해준다. RIU 내부의 전력분배 부분에서(RWA S/W) 릴레이 스위치를 동작하여 RWA를 켜고 끄는 일을 수행한다.

RWA는 디지털 데이터 통신을 이용하여 명령 을 송수신하고 구동되는데, 스탠바이 모드, 속도 구동 모드, 토크구동 모드의 3가지 운용모드를 가진다. RS485 규격의 통신회선을 이용하여 비동 기 방식으로 RWA에 전송되는 명령은 제조사에

표 1. 과학기술위성2호의 반작용 휠 제원

\begin{tabular}{|l|l|}
\hline \multicolumn{1}{|c|}{ 항목 } & \multicolumn{1}{c|}{ 내용 } \\
\hline 각운동량 저장 & $0.12 \mathrm{Nms}(2800 \mathrm{rpm})$ \\
\hline 속도범위 & $\pm 2800 \mathrm{rpm}$ \\
\hline 반작용토크 & $5 \mathrm{mNm}(2800 \mathrm{rpm})$ \\
\hline 전력소비 & $\begin{array}{l}+20 \mathrm{~V}-0.5 \mathrm{~V},<0.15 \mathrm{~A} \\
+5 \mathrm{~V} \pm 0.25 \mathrm{~V},<0.12 \mathrm{~A}\end{array}$ \\
\hline 온도범위 & $-20^{\circ} \mathrm{C}+60^{\circ} \mathrm{C}$ \\
\hline 통신방법 & $\mathrm{RS} 485$, full duplex $(9600, \mathrm{n}, 8,1)$ \\
\hline 외경 & $95 \mathrm{~mm}$ \\
\hline 높이 & $102 \mathrm{~mm}$ \\
\hline 무게 & $<0.7 \mathrm{~kg}$ \\
\hline
\end{tabular}

서 정해놓은 프레임 구조로 되어있으며, 프레임 내부에 RWA의 주소와 명령번호, 설정값 등으로 데이터가 구분되어 나누어져 있다. 이 데이터 프 레임의 구조는 위성에서 사용하는 데이터 구조와 다르며 RWA과 통신하기 위해서는 위성에서 사 용하는 데이터 프레임과 RWA 데이터 프레임을 중간에서 변환해주는 프로그램이 필요하다.

\section{2 반작용 휠 인터페이스 유닛(RIU)}

RWA를 위성 시스템과 연결해주는 중간 인터 페이스를 담당하는 유닛으로 과학기술위성2호의 PSU2에서 반작용 휠 구동을 위한 $+20[\mathrm{~V}],+5[\mathrm{~V}]$ 의 전원을 공급받는다. 이 전원은 외부 명령에 의해서 릴레이와 필터로 구성된 RWA S/W를 통과하여 4 개의 반작용 휠에 각각 전원을 공급하 게 된다

그림 2의 가운데 붉은선 내부가 RIU이다. RWA 에 전달되는 명령은 $\mathrm{OBC}$ 에서 수신하며, RIU 내 부에 $\mathrm{Mux}$ 를 두어서 통신회선을 주컴퓨터와 부 컴퓨터 중 선택하여 전환할 수 있다.

이렇게 $\mathrm{OBC}$ 에서 수신한 명령은 RS485 규격에 맞는 물리적인 통신 회선을 통하여 RWA에 전송 된다. RWA 제조회사에서 정해놓은 RWA 통신 데이터 프레임에 맞춰서 $\mathrm{OBC}$ 가 명령을 전송하 면, 그에 상응하는 동작이 RWA에서 일어나게 된다. 또한 반작용휠에 공급되는 전원의 접지를 분리하기 위하여 각각의 통신 회선과 명령회선은 옵토커플러로 분리되어 구현하였다.

\section{3. 엔지니어링 모델 시험}

\section{1 벤치 시험(Bench Test)}

위에서 요구되는 기능에 맞춰 개발된 RIU EM 은 그림 3의 구성으로 벤치 시험을 수행하였다.

시험 환경에서 $\mathrm{RWA}$ 의 전원은 과학기술위성2 호 PSU2 EM에서 공급받아 RIU를 통하여 제공

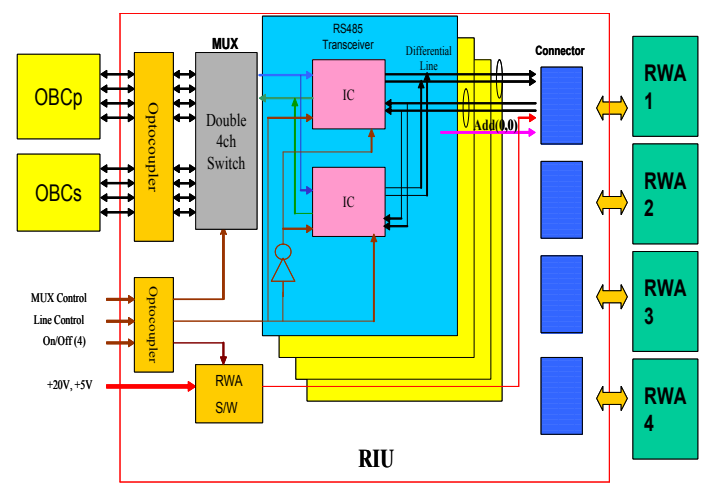

그림 2. 반작용휠 인터페이스 유닛 구성 


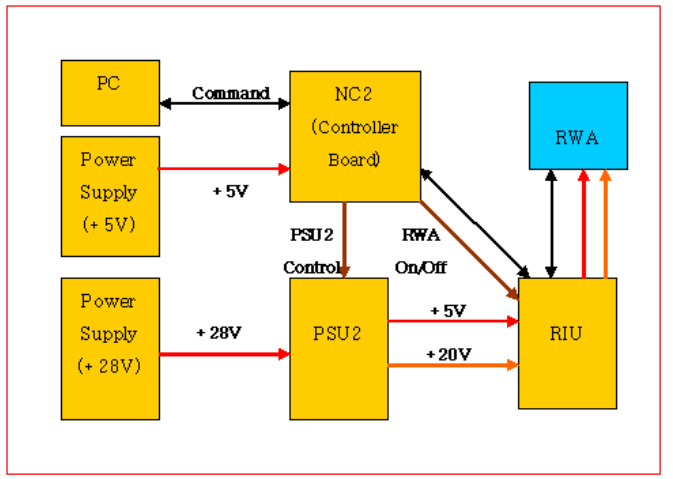

그림 3. RIU EM Bench Test Setting

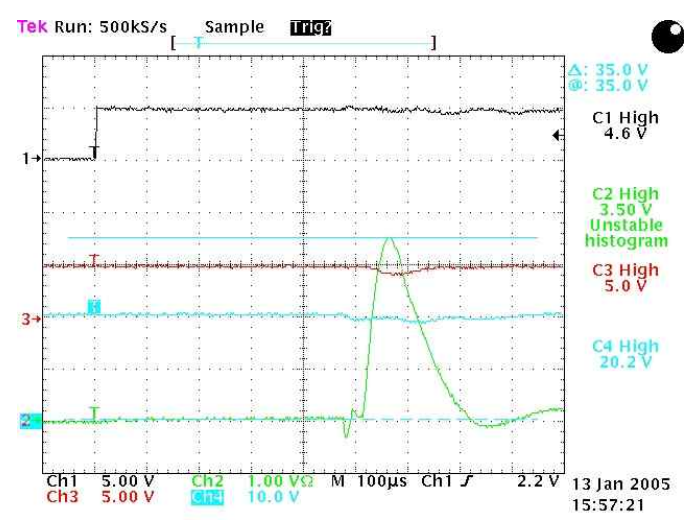

그림 4. $+5[\mathrm{~V}]$ Inrush Current

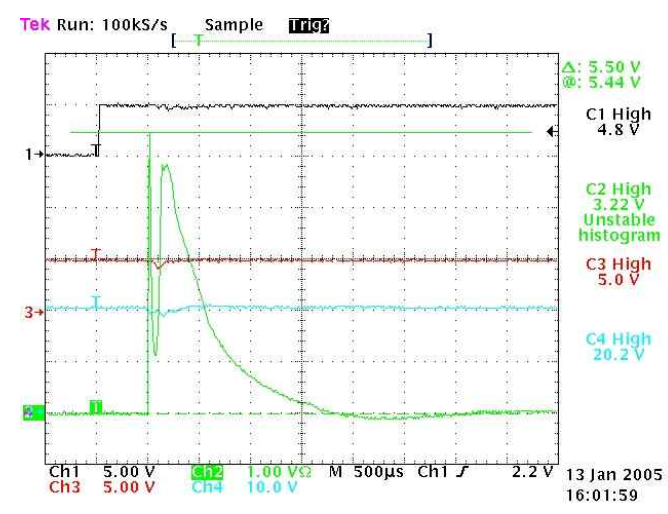

그림 5. +20[V] Inrush Current

된다. 과학기술위성2호 $\mathrm{OBC}$ 가 담당하는 RWA 명령 송신은 과학기술위성1호 NC2(Node Controller 2) $\mathrm{QM}(\mathrm{Qualifying}$ Model)이 대신하였으며, 과학 기술위성2호 TCU가 담당하는 RWA S/W control 및 PSU2 control 역시 과학기술위성1호 $\mathrm{NC} 2$ 가 담당하였다.
$\mathrm{PC}$ 에서 내려진 명령으로 $\mathrm{PSU} 2$ 에 장착된 $\mathrm{DC} / \mathrm{DC}$ converter가 enable 되면 RIU에 +20[V] 와 $+5[\mathrm{~V}]$ 의 전원이 인가된다. 이어서 RIU에 있는 릴레이 스위치를 켜면 RWA의 구동을 위한 비가 완료된다.

RWA S/W인 릴레이가 켜지는 순간 전원단의 전압과 전류 파형을 측정하여 보면 그림 4 와 같 은 순간적인 전류 유입을 확인할 수 있다.

그림 4 의 채널 $1(\mathrm{C} 1)$ 은 릴레이 스위치를 동작 하는 신호이며 그에따라 채널2(C2)에 순간적으 로 3.5[A]의 전류가 유입되는 것을 알 수 있으며 채널 $3(\mathrm{C} 3)$ 에 나타나는 $+5[\mathrm{~V}]$ 전압이 약 $0.8[\mathrm{~V}]$ 떨어지는 것을 확인할 수 있다. RWA의 Inrussh Current에 대한 요구조건은 없지만 이때 떨어진 전압이 표 1 의 전원 범위를 벗어나는 수치로 순 간적인 RWA 내부 제어회로의 불안을 초래할 수 있다. 하지만 RWA는 한번 켜게 되면 특별한 이유없이 끄는 상황이 발생하지 않으며 초기의 순간적인 불안이 정상운용에는 지장을 주지 않 는다.

그림 5 는 채널 $1(\mathrm{C} 1)$ 릴레이 동작 신호에 따라 채널2(C2)에 5.5[A] 이상의 순간적인 전류 유입 이 일어남을 확인한 것이다. 이때 유입돼는 전류 는 수 밀리초[msec]의 시간이 지나기 전에 정상 상태로 들어섬을 확인할 수 있다. PSU2에 공급 되는 $+28[\mathrm{~V}]$ 의 전압은 전체 위성에 공통으로 연 결되는 것으로, 그 하위단에 연결된 RWA의 동 작으로 인하여 이 메인 전원이 영향을 받으면 나 머지 하위 시스템의 전원 입력부에 잡음으로 작 용하여 하위단의 불안정을 초래할 수 있다.

그림 6 은 채널 $1(\mathrm{C} 1)$ 의 신호로 RWA S/W가 동 작할 때 PSU2의 메인 전압인 채널 $4(\mathrm{C} 4)$ 의 $+28[\mathrm{~V}]$ 가 받는 영향을 보여준다. RWA에 유입되 는 순간 전류로 인하여 PSU2의 $+28[\mathrm{~V}]$ 전압은 약 $1[\mathrm{~V}]$ 정도 떨어지는 것을 확인할 수 있다. 이 때 시험에 사용된 전원공급장치(그림 3의 Power Supply)의 전류 용량은 5.2[A]로 설정된 것이다. 이 현상은 RWA 한 개를 켤 때 발생한 것이며 위성에서 사용하는 4 개의 RWA를 동시에 키게 된다면 그 영향은 증폭되어 나타나게 된다. RWA S/W 가 켜진 후 PC를 통하여 명령을 전 송하고 RWA의 동작을 확인한다. 정해진 데이터 프레임을 RWA에 전송하면 RWA는 속도를 증감 하거나 토르크 발생 등의 정상동작을 수행한다. 명령 전달의 확인은 우선 RS485 규격에 맞게 물 리적인 신호가 전송되는 지를 파악하는 것이 중 요하며, 명령을 받은 RWA는 동작의 수행과 함 께 그 응답을 회신한다. 


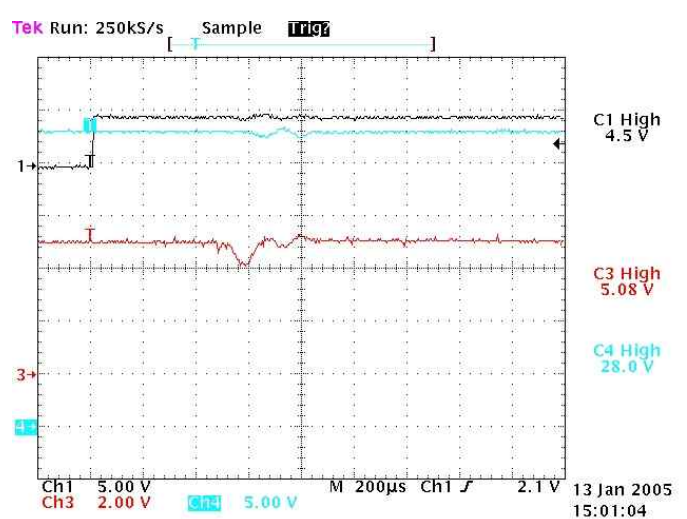

그림 6. PSU2 +28[V] 전압

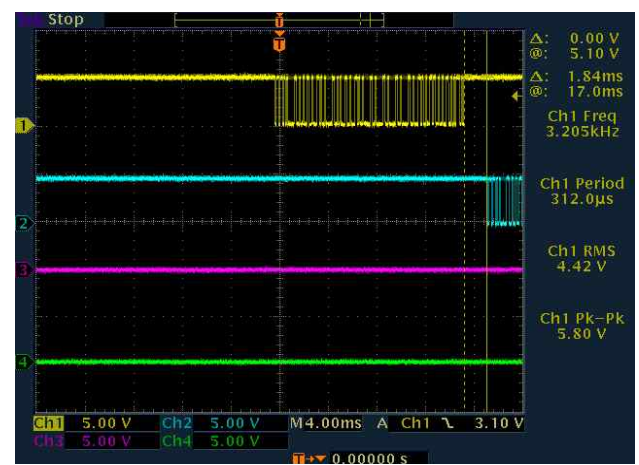

그림 7. RWA 통신 파형

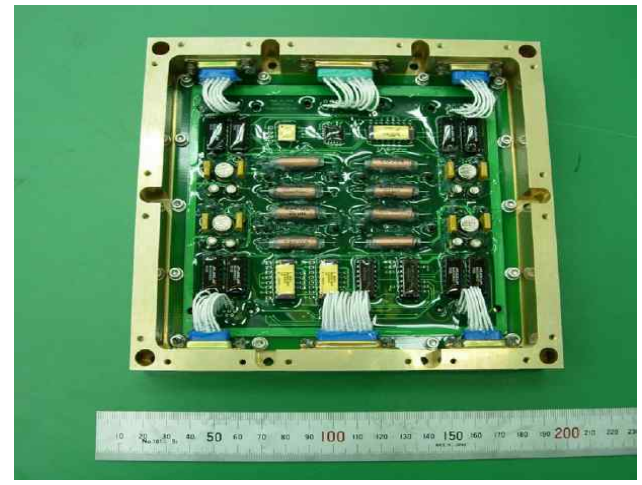

그림 8. 과학기술위성2호 RIU PFM 사진

그림 7의 채널1(Ch1)은 PC를 통해 보낸 명령이 RIU의 RS485 Transceiver 최종단에서 RWA에 전송되는 파형을 보여주는 것이며, 채널2(Ch2)는 그에 따른 RWA의 응답을 보여준다.

\section{$3.2 \mathrm{EM}$ 시험 결과}

개발이 완료된 RIU $\mathrm{EM}$ 은 과학기술위성2호 $\mathrm{EM}$ 펼친 모델 시험을 통하여 전체 시스템과 연

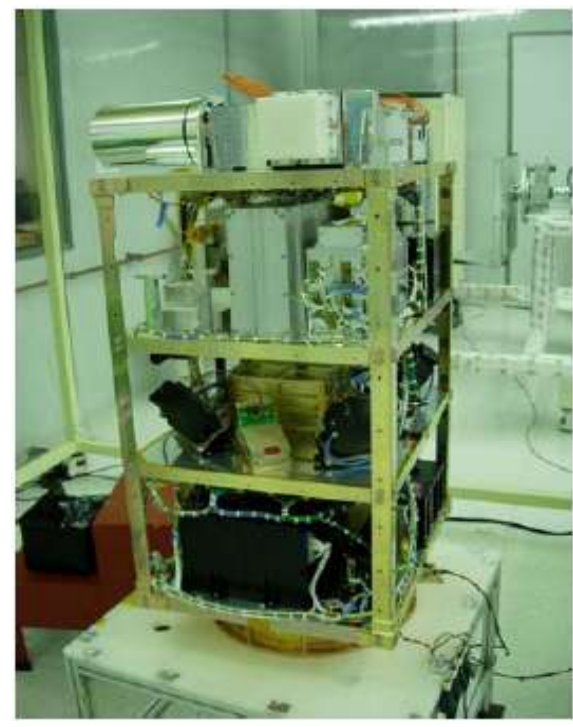

그림 9. 과학기술위성2호 PFM 조립사진

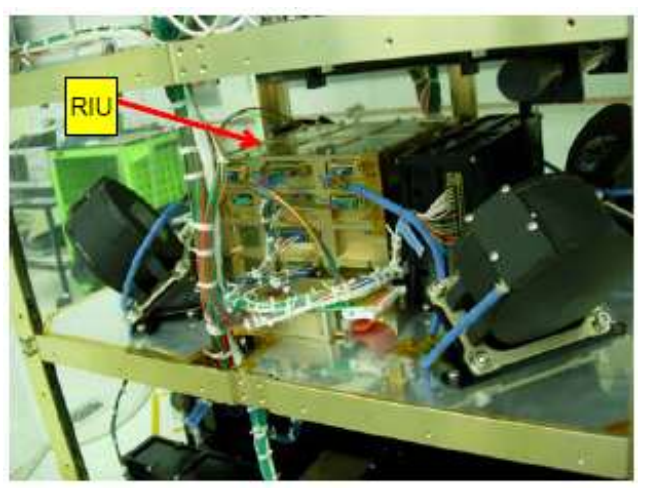

그림 10. 과학기술위성2호 RIU/RWA PFM 조립 사진

결 및 시험을 수행하였다. 벤치에서 수행하였던 일련의 시험을 실제 과학기술위성2호 유닛(Unit) 들을 이용하여 수행한 것이며, 시스템 인테그레 이션과 안정성에 문제가 없음을 확인하였다.

\section{III. 결 론}

과학기술위성 2호의 RIU EM이 개발 및 테스 트가 완료되었다. 개발된 RIU EM은 RWA와 위 성 시스템을 안정적으로 연결하는 역할을 수행하 며, 위성의 핵심적인 구동기인 RWA가 정상적으 로 운용될 수 있게 해준다.

RWA S/W를 켤때 발생하는 PSU2 +28[V] 전 원의 영향은 추가적인 실험이 필요한 부분이며, 
4 개의 RWA를 동시에 키는 것을 피하여 시간 간 격을 두고 순차적으로 켜서 그 영향을 줄이는 것 이 필요하다고 생각한다.

현재 과학기술위성2호 PFM(Proto Flight Model) 이 제작되어 열진공 시험을 무사히 마친 상태이 며 RIU 역시 완벽한 동작상태를 보여주어 실제 우주환경에서 그 기능을 충분히 발휘할 수 있게 검증되었다.

\section{후 기}

본 기술논문은 과학기술부 과학기술위성 2 호 개발사업의 예산을 받아 작성되었습니다.

\section{참고문헌}

1) "Technical Description of Reaction Wheel Assembly RSI 01-5/28", TELDIX.

2) "STSAT-1 RCU/NC2 Hardware EIDP K4-AC-EDH-201" 과학기술위성1호 EIDP.

3) "STSAT-2 Preliminary Design Review", 한 국과학기술원 인공위성연구센터, 한국우주과학회 지, 2003. 